IRA-International Journal of Applied Sciences ISSN 2455-4499; Vol.05, Issue 02 (2016)

Institute of Research Advances

Pg. no. 57-65

http://research-advances.org/index.php/IRAJAS

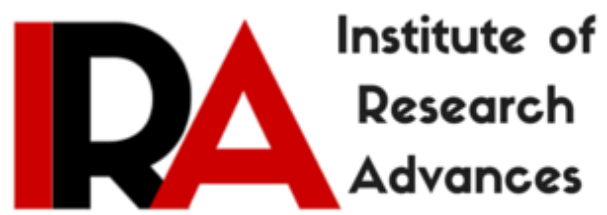

\title{
Efficient Removal of Dyes Using Almond Husk as a Natural Adsorbent
}

\author{
${ }^{1}$ Bhanuprakash M. and ${ }^{2}$ Belagali S.L. \\ ${ }^{1,2}$ Environmental Chemistry Laboratory, Department of Studies in Environmental \\ Science, University of Mysore, Manasagangotri, Mysuru-570 006, Karnataka, \\ India.
}

Type of Review: Peer Reviewed.

DOI: http://dx.doi.org/10.21013/jas.v5.n2.p1

\section{How to cite this paper:}

M., Bhanuprakash, \& S.L., Belagali (2016). Efficient Removal of Dyes Using Almond Husk as a Natural Adsorbent. IRA-International Journal of Applied Sciences (ISSN 24554499), 5(2), 57-65. doi:http://dx.doi.org/10.21013/jas.v5.n2.p1

(C) Institute of Research Advances

\section{(cc) EY-NC}

This work is licensed under a Creative Commons Attribution-Non Commercial 4.0 International License subject to proper citation to the publication source of the work.

Disclaimer: The scholarly papers as reviewed and published by the Institute of Research Advances (IRA) are the views and opinions of their respective authors and are not the views or opinions of the IRA. The IRA disclaims of any harm or loss caused due to the published content to any party. 


\section{ABSTRACT}

Industrialization and urbanization is considered as, one of major threat to pollution of air, soil and water systems. Among these, water pollution is considered as important one. The addition of various pollutants to water resources is considered as major threat for deterioration of water quality and makes it unsuitable for domestic purposes. Out of many water pollutants, dyes are considered as most hazardous for the plants, animals and human beings. So, it is very important to conserve water due to limited availability. In the present study, almond husk was neutraceutical spent used as adsorbent for the removal of dyes from aqueous solutions in batch mode experiments. Parameters like contact time, pH, adsorbent concentration, adsorbent dose were studied. The results show that, almond husk is a very good adsorbent for the removal of dyes from the aqueous medium. The adsorption isotherms like Freudlich and Langmuir model were calculated and found to be favorable.

Key words: Almond husk, adsorbent, batch mode, dose, adsorption

\section{Introduction:}

As the world has industrialized and population has grown, water become more vital. The effect of this rapid growth has resulted into environmental problems with many types of pollution including water pollution. The government is more concerned to water problem because the effect of the pollution will harm environment. There are a number of pollutants which cause water pollution. All pollutants usually come from manufacturing factories such as textile, petroleum, agriculture, municipal and food industries.

Many industries, especially textile, pulp and paper industries, often use dyes and pigments to color their products. Fifteen percent of the total world production of dyes is lost during the dyeing process and is released in textile effluents (Zollinger, 1987). Most dyes are inert and non-toxic, at the concentrations discharged into the receiving water; however, they impart color undesirable to the water user. The release of these colored wastewaters in the ecosystem is a dramatic source of esthetic pollution, like eutorphication and perturbations of aquatic life.

The effluent from dye stuff manufacture and certain other industries, like textile, pulp and paper dyeing, printing and leather industries contain small amount of dyes (Shriram Chaurasia and Shashikant, 2007)

Industries use dyes to color their products, as a result the residual and unspent dyes are discharged into the environment, particularly to aquatic body. Color is the most obvious indicator of water pollution. Wastewater from dyeing and finishing operations in the textile industry is generally high in both color and organic content. Most of the dyes have complex aromatic structures, which are resistant to light, biological activity and other degradative processes and hence not readily removed by typical waste treatment processes.

The possible long term effects of few dyes and dye degradation products are of great concern. Some of them are skin irritating mutagenic, carcinogenic and allergic dermatitis. Over $90 \%$ of some 4000 dyes tested in Ecological and Toxicological Association of dyes (ETAD) survey had LD50 (Lethal Dose at $50 \%$ survival) values greater than $2 \times 10^{3} \mathrm{mg} / \mathrm{kg}$. The highest rates of toxicity were found among basic diazotizes. Unless and otherwise properly treated, dyes can significantly affect photosynthetic activity in aquatic life due to presence of metals and chlorides in them. The decolourization of textile industries wastewater is a worldwide problem. Various treatment methods for removal of colours and dyes are coagulation, ozonisation, membrane separation, anaerobic decolourisation, oxidation, flocculation and adsorption. Among all these methods, adsorption appears to be the best process for overall treatment of dyes stuff effluent (Sonawane \& Shrivastava, 2009) 
Adsorption has evolved as one of the most effective physical process for removal of dyes. The number of adsorbents like Chewing Tobacco (Geeta K.S and Belagali S.L ,2011), Hazlenut shells (Fathi and Asfaram, 2011), Sugarcane bagasse(Sachin Kanawade and Gaikwad, 2011), Egg shell (Geeta and Belagali, 2012), Potatohusk (Pooj Shrivastava, 2012 ), Aspergillus tamari (El-Batal, 2012), Rice Husk ( Shafiqul Alam et al, 2012), Shale ( Jareeya yimrattanabovorn et al, 2012), Biomass ( Murugan and Ganapathy, 2012), Composite adsorbent ( Jayanta kumar basu et al, 2012), Chitosan montmorillonite (Roiskiono slamet and erdawati ,2013), Low cost adsorbents (Ramakrishnaiah and Arpitha , 2014), Coral wood tree legume (Bhanuprakash et al, 2015).

Literature survey reveals that, almond husk has not been used as an adsorbent. So, I concentrated on this material.

\section{Materials and Methods:}

\section{Processing of the Adsorbent for the study:}

Almond husk was collected in bakery and sweets shop, it was washed with water and dried in sunlight followed by hot air oven at $100^{\circ} \mathrm{C}$. Dried husk was broken into small pieces by hand; it was then powdered by the mixer grinder for 10-15 min. It was then sieved. Uniform particle size of adsorbent was used for adsorption, which were treated with $2 \mathrm{~N} \mathrm{HCl}$ and $2 \mathrm{~N} \mathrm{NaOH}$ solutions for half an hour. The adsorbent was washed thoroughly with distilled water.

\section{Preparation of dye solutions:}

$10 \mathrm{mg}$ of dye was weighed and dissolved in $100 \mathrm{ml}$ of distilled water to give $100 \mathrm{ppm}$ of dye solutions which was diluted for required concentrations. The preparation procedure was same for all the dyes

For the analysis of the dye and adsorbent of sample, we used simplest possible equipments, one can have in a lab. The instruments like $\mathrm{pH}$ meter and Systronics UV-visible spectrophotometer 118 were used. For the surface analysis, to confirm adsorption, Scanning Electron Microscope was used.

\section{Experimental section:}

\section{Batch Experiment:}

Dyes adsorption experiments were conducted in batch mode with $100 \mathrm{ml}$ stock solution. The variables studied were adsorbent dose, concentration of adsorbate, $\mathrm{pH}$ and contact time. The dye solution and adsorbents were used for adsorption process after keeping the solution aside for adsorption to take place.

Five numbers of $25 \mathrm{ml}$ samples of $10 \mathrm{ppm} / \mathrm{L}$ dye solutions were taken in beakers and $0.25 \mathrm{~g}-1.25 \mathrm{~g}$ of dose of adsorbent was added and studied for adsorption.

Constant dose of adsorbent $(0.25 \mathrm{~g})$ was separately added to $25 \mathrm{ml}$ samples with different concentrations of dye solutions $(2,4,6,8$ and $10 \mathrm{ppm})$ in 5 beakers, at room temperature and studied the adsorption process. Five numbers of $25 \mathrm{ml}$ samples of dye solutions from 2-10 ppm and varying doses of adsorbents from $0.25 \mathrm{~g}-1.25 \mathrm{~g}$ were added in series. Then, the solutions were kept for adsorption to take place. The effect of contact time with $0.25 \mathrm{~g}$ of adsorbent dose in $25 \mathrm{ml}$ of $10 \mathrm{ppm}$ dye solution was studied.

\section{Adsorption isotherms:}

In order to determine the sorption potential of adsorbent, the study of sorption isotherm was essential in 
selecting an adsorbent for the removal of the dyes. The adsorption process was studied with the Freudlich and Langmuir isotherms (Adamson, 1960).

Freudlich isotherm: $\log q_{e}=\log K+\left(1 / n \log C_{e}\right)$

Langmuir isotherm: $\left(C_{\mathrm{e}} / \mathbf{q}_{\mathrm{e}}\right)=\left(\mathrm{l} / \mathbf{Q}_{\mathbf{0}} \mathbf{b}\right)+\left(\mathrm{C}_{\mathrm{e}} / \mathbf{Q}_{\mathbf{0}}\right)$

where, qe is the amount of dye adsorbed per unit mass of adsorbent at equilibrium (in $\mathrm{mg} / \mathrm{g}$ ), $\mathrm{K}$ and $\mathrm{n}$ are respectively the measures of sorption capacity and intensity of adsorption, $\mathrm{C}_{\mathrm{e}}$ is the equilibrium concentration of dyes (in $\mathrm{mg} / \mathrm{L}$ ) and $\mathrm{Q}_{\mathrm{o}}$ and $\mathrm{b}$ are the Langmuir constants indicating the sorption capacity (in $\mathrm{mg} / \mathrm{g}$ ) and energy of adsorption (in $\mathrm{gm} / \mathrm{L}$ ) respectively from the slope and intercept.

\section{Kinetics of the adsorption:}

The adsorption kinetics was found to be of first order. The following equation proposed by Kannan and Vanamudi (1991) was employed for adsorption data:

$$
K=\left(\frac{2.303}{t}\right) \log \left(\frac{C_{0}}{C_{t}}\right)
$$

where, $C_{o}$ and $C_{t}$ are concentrations of dyes at zero time and at time $t(\mathrm{~min})$. The values of $\log \left(\mathrm{C}_{\mathrm{o}} / \mathrm{C}_{\mathrm{t}}\right)$ were found to be linearly correlated with the contact time for all the above dyes.

Further, the essential characteristics of the Langmuir isotherm can be described in terms of a dimensionless constant, namely separation factor or equilibrium parameter, $\mathrm{R}_{\mathrm{L}}$ which was defined by Weber and Chakravorti (1974) in the equation: $R_{L}=1 /\left(1+b c_{i}\right)$, where, $b$ is the Langmuir constant and $c_{i}$ is the initial concentration of dye (in $\mathrm{ppm}$ ). The value of the parameter, $\mathrm{R}_{\mathrm{L}}$ indicates the nature of the isotherm as given below.

Standard $\mathrm{R}_{\mathrm{L}}$ value which indicates the nature of the developed Model

\begin{tabular}{ll}
$\mathrm{R}_{\mathrm{L}}$ value & Nature of isotherm \\
\hline & \\
$\mathrm{R}_{\mathrm{L}}>1$ & Unfavorable \\
$0<\mathrm{R}_{\mathrm{L}}<1$ & Linear \\
$\mathrm{R}_{\mathrm{L}}=1$ & Favorable \\
$\mathrm{R}_{\mathrm{L}}=0$ & Irreversible \\
\hline
\end{tabular}

\section{RESULTS AND DISCUSSION:}

For an adsorbent, the rate of adsorption varies with different conditions used for adsorption. i.e. $\mathrm{pH}$, adsorbent dose, concentration, contact time etc. In the present work, adsorption study was carried out at different conditions and its effect on the adsorption rate is determined.

1. Effect of $\mathrm{pH}$ on the rate of adsorption.

The table shows the time taken for the different dyes at acidic, neutral and basic media. 


\begin{tabular}{llll}
\hline Dyes used & \multicolumn{3}{l}{ Adsorption time at different pH } \\
\cline { 2 - 4 } & $\begin{array}{l}\text { Acidic } \\
(\mathrm{hrs})\end{array}$ & $\begin{array}{l}\text { Neutral } \\
(\mathrm{hrs})\end{array}$ & $\begin{array}{l}\text { Basic } \\
(\mathrm{hrs} .)\end{array}$ \\
Fuschin basic & LA & 6 & LA \\
Janus green & 6 & LA & LA \\
Indigo caramine & 6 & LA & LA \\
Metanil yellow & 8 & LA & LA \\
\hline
\end{tabular}

Note: LA-less adsorption

From the data: 'Janus green, Indigo caramine and Metanil yellow 'dyes adsorbed at faster rate in acidic medium. Except Fuchsin basic adsorbed in neutral media.

\section{Effect of adsorbent dose:}

Five numbers of $25 \mathrm{ml}$ samples of $1 \%$ dye solutions were taken in beakers and 0.25 to $1.25 \mathrm{~g}$ of dose of adsorbents were added and studied for adsorption.

In case of all dyes, as dose increased, adsorption increased (Fig. 1).

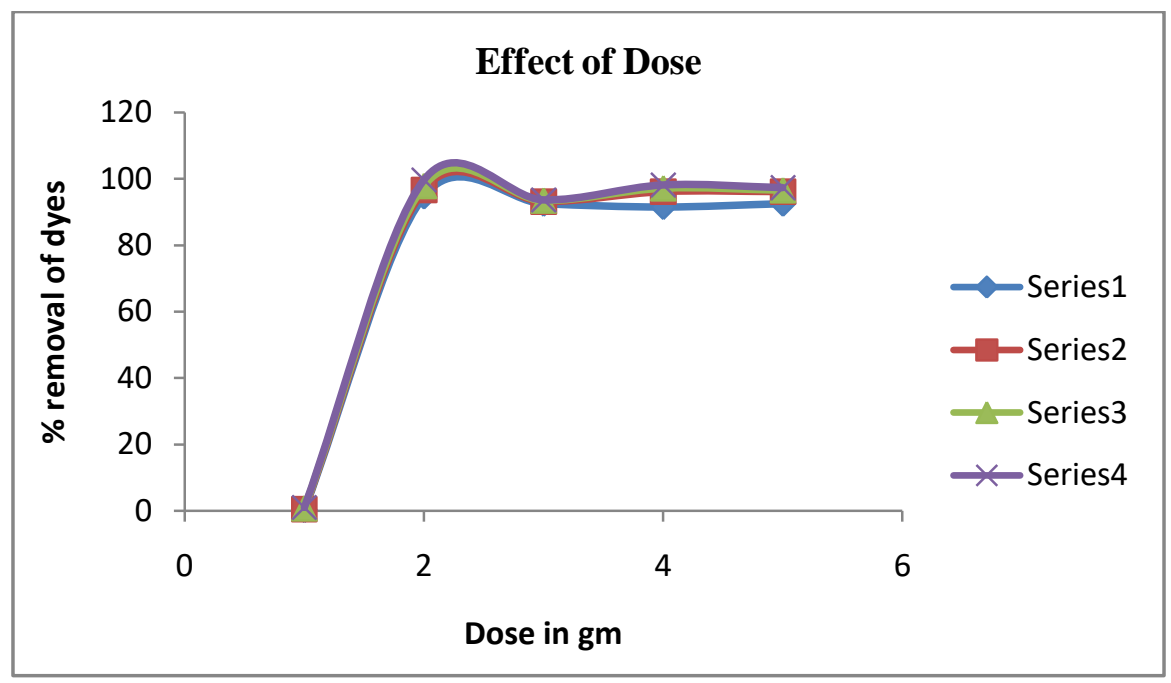

Fig-1: Graph showing effect of dose for all dyes.

\section{Effect of concentration:}

Constant dose of adsorbents $(0.25 \mathrm{~g})$ were separately added to $25 \mathrm{ml}$ samples with different concentrations of dye solutions $(2-5 \%)$ contained in 5 beakers at room temperature and studied the adsorption process, which indicates that, as concentration increases the adsorption decreases for all the adsorbents and dye solutions (Fig. 2). 
As concentration increases the adsorption rate decreases for all dye solutions.

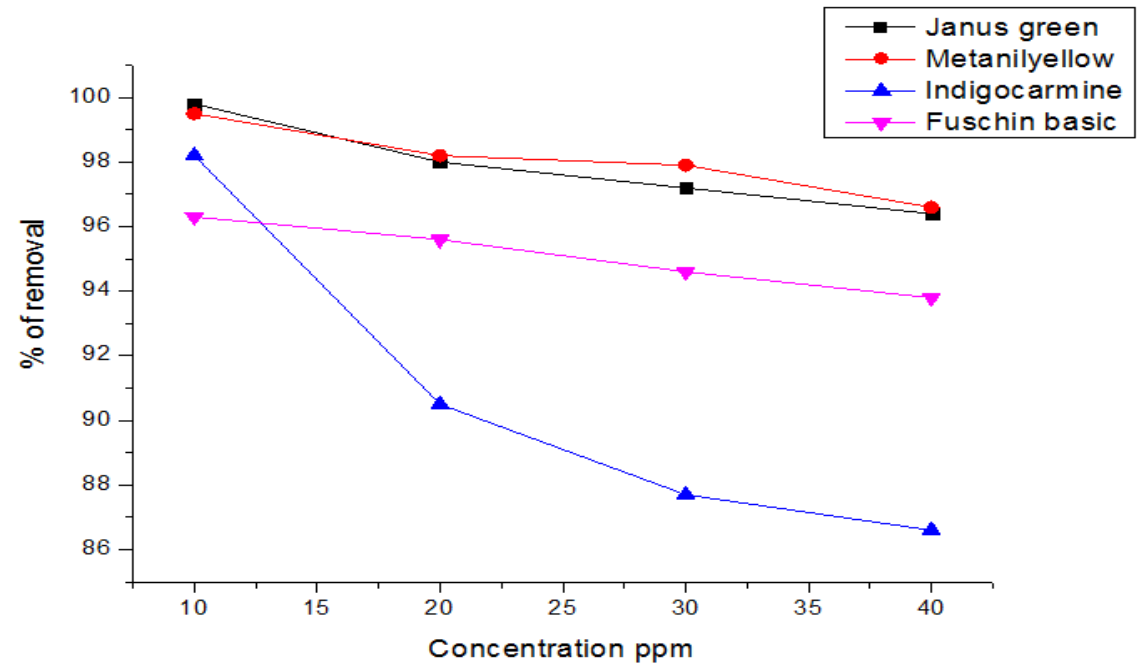

Fig-2: Graph showing effect of concentration for all dyes

\section{Effect of Dose v/s Concentration:}

Five number of $25 \mathrm{ml}$ samples of dye solutions (2-5\%) and varying doses of adsorbents $(0.25 \mathrm{~g}-1.25 \mathrm{~g})$ were added in series. Then, the solutions were kept for adsorption process to take place. The results are shown in Fig. 3, which indicate that, the dose and the concentration of all the dye solutions, for all the adsorbents are co-related to each other (Fig. 3)

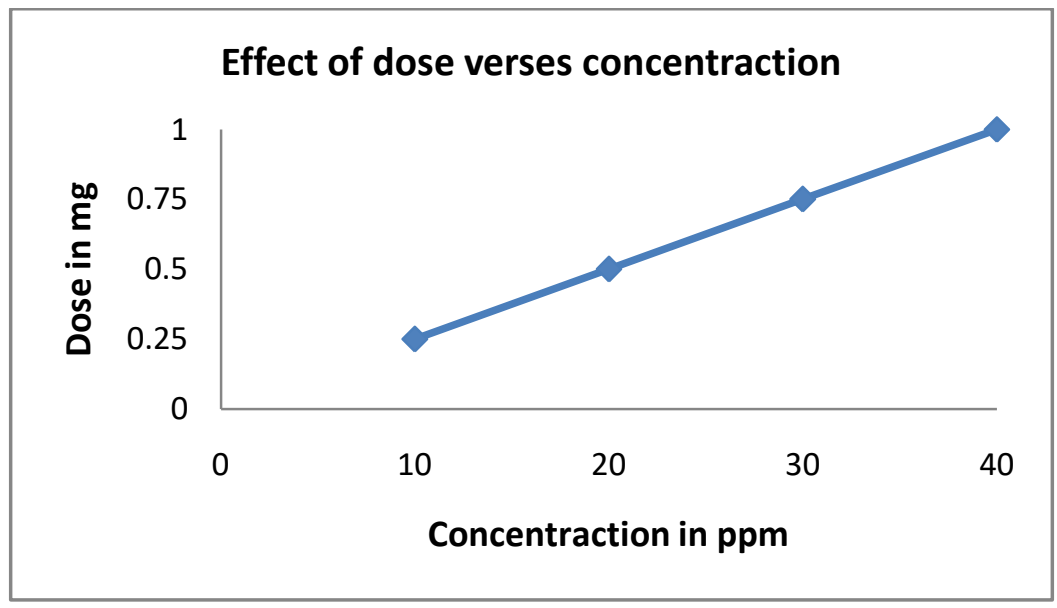

Fig-3: Graph showing effect of Dose v/s Concentration for all dyes

\section{Effect of contact time:}

The effect of contact time with $0.25 \mathrm{~g}$ adsorbent dose in $25 \mathrm{ml}$ of $10 \mathrm{ppm}$ dye solutions was investigated. The adsorption increased with increase in time. Contact time of all dye solutions was within $12 \mathrm{hrs}$. The adsorption increased with increase in contact period. 


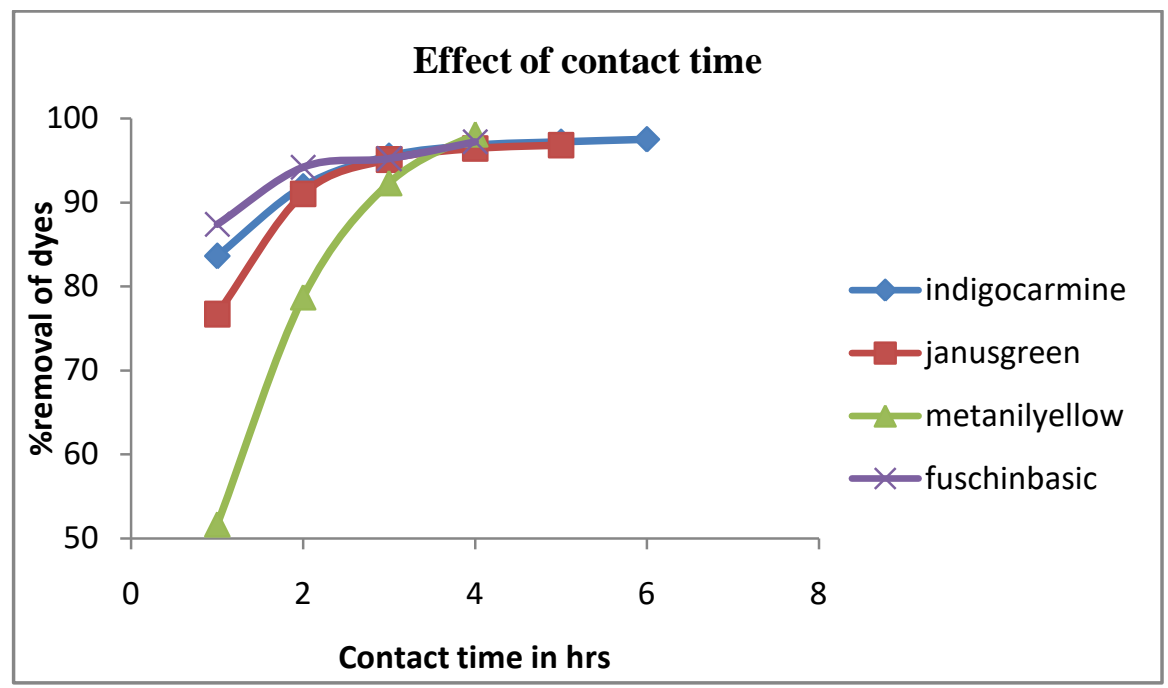

Fig-3: Graph showing effect of contact time for all dyes.

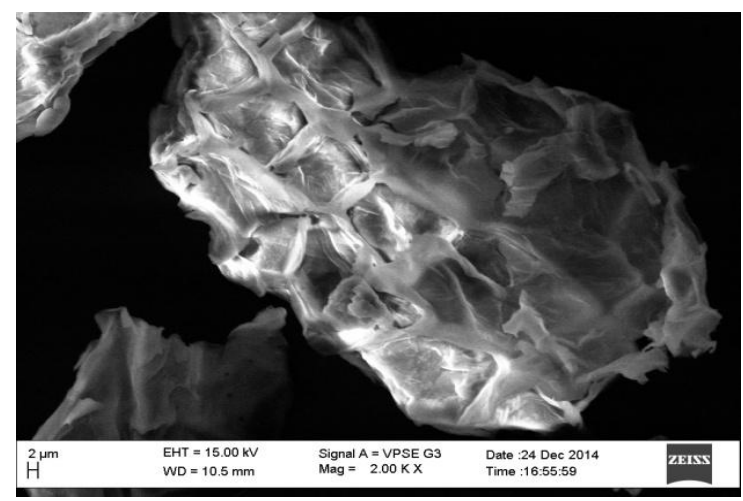

Figure 1. Unadsorbed adsorbent adsorbent

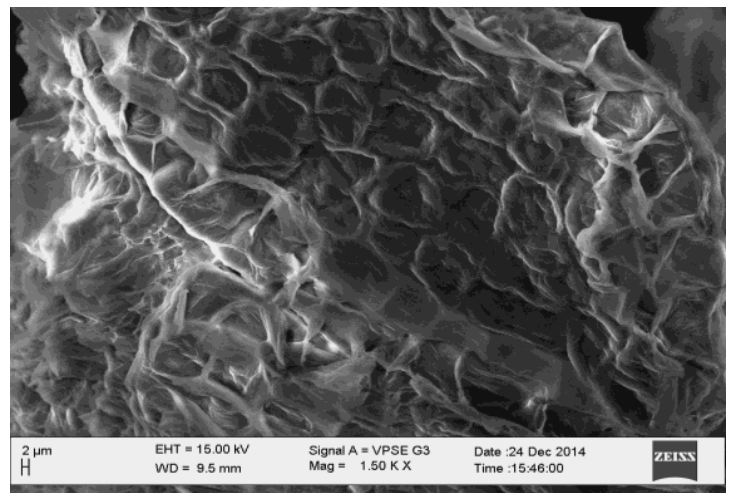

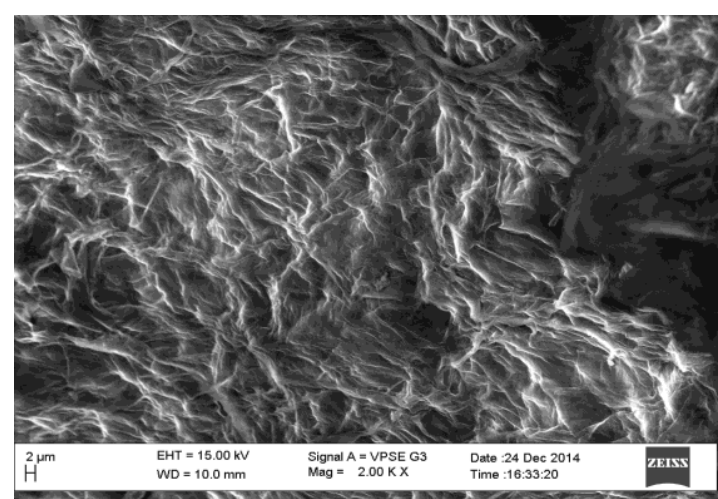

Figure 2. Metanil yellow adsorbed

Figure 3. Indigo caramine adsorbed adsorbent

The scanning electronic microscope image shows that, there is more cavity structure (active sites) in unadsorbed material, in adsorbed material the cavity structures ( active sites) are covered by dyes. From this study, it can concluded that, the color removal from Almond husk is adsorbtion process 
IRA-International Journal of Applied Sciences

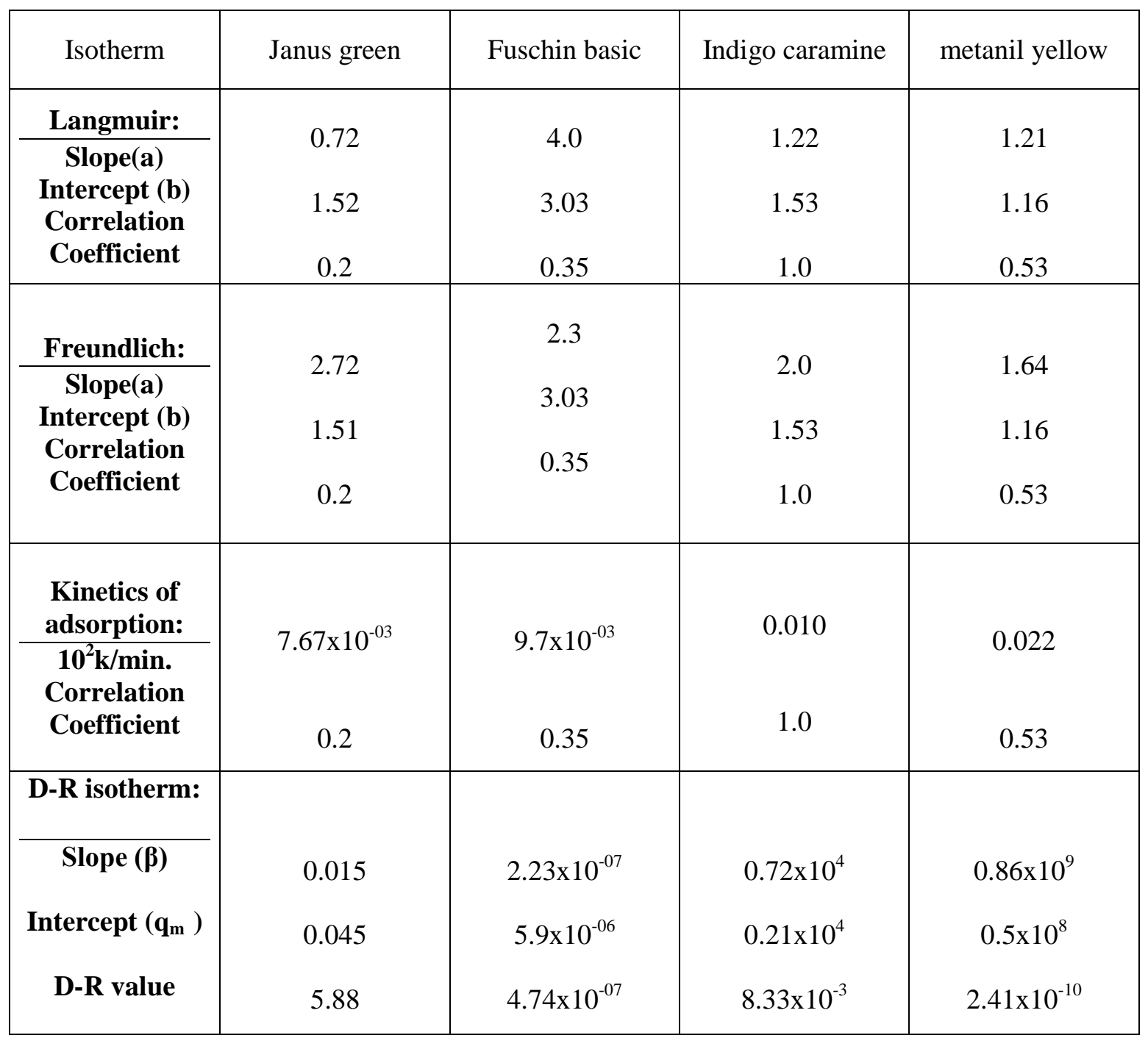

\section{Conclusion}

Almond husk is a neutraceutical which is a waste generated from processing of almond and we have utilized the material for efficient removal of colour from aqueous media. The results show that, almond husk is a very good adsorbent for the removal of dyes from the aqueous media. The adsorption isotherm freundlich appears to be good for the adsorption of dyes from the adsorbent.

\section{ACKNOWLEDGEMENT}

One of the Authors, Mr. Bhanuprakash M, is grateful to UGC Non-NET fellowship scheme for providing financial support, from UGC through Mysore University, Mysore.

\section{REFERENCES:}

1. Bhanuprakash $\mathbf{M}^{*}$, Belagali S.L and Geeta K.S. The Ecoscan, $8(1 \& 2), 2015$ (123-126).

2. Bhanuprakash $\mathrm{M}^{*}$, Belagali S.L. International J. of innovative rese. in Sci. Engg. \& Tech. , 5(1), 2016 (567-563).

3. Pooja and Shrivastava 2012. Study on color removal of basic dye by potato husk as an Adsorbent, J. Chem. Biologl. and Phys. Science. 2(2), 597-600.

4. Geetha K.S. and Belagali S.L. 2012. Adsorption studies of some metals and dyes on Garlic 
Husk a cheap adsorbent, The Ecoscan, 4(land2), 189-193.

5. Geetha K.S. and Belagali S.L. 2012. Removal of some heavy metals from aqueous effluents by adsorption on egg shells, Pollution Research, 31(1). 111-116.

6. Rezamarandi, Seyedeh Marjan and Bakhtiar Sepehr 2011. Removal of orange dye from Waste water used by Natural Adsorbent of Moringa Oleifera Seeds, American J. Env. Engg. 1(1): 1-9.

7. Geetha K.S. and Belagali S.L. 2011. Dyes adsorption study on natural adsorbent -Chewing Tobacco, The Ekologia. 11(1-2). 47-54.

8. Elass K., Laachach A., Alaoui. A.-Azzim 2010. Removal of methylene blue from aqueous solution using Ghassoul, a Low-cost adsorbent. J, of Appld. Ecolg. And Env. Research. 8(2): 153-163.

9. Sonawane G.H, and Shrivastava V.S. 2009. Removal of Basic Dye (Methylene blue) from aqueous solution by adsorption using Musa paradisica: a agricultural waste. J.Env.Sci and Engg. 51(1), 45-52.

10. Luisa A. Sepulveda-Cuevas, Elsa G. Contreras-villacura and carolyln. L. Palma - Toloza 2008. Magellant peat as natural adsorbent of recalcitran synthetic dyes, J.soil.Sc.plant Nutr. (2):31-43

11. Chaurasia S. and Shashikant 2007. Removal of Basic dye from aqueous solution using Natural Adsorbent: Equilibrium and Diffusion studies, Indian J. Environ. Protection, 27(6), 538-544.

12. Liew Abdullah A.G, M.A. Mohd Salleh, Siti mazlina M.K, Mohd Noor M.j, Oswan M.R, Wagiran R., and Sobri S. 2005. Azo dye removal by adsorption using Waste biomass sugarcane Bagasse., International. J. Engg. \& Tech. 2(1) PP.8-13.

13. Tabrez A Khan, Ved Vati Singh and Kumar D. 2004. Removal of some basic dyes from artificial textile waste water by adsorption on Akash Kinari Coal, J. of Scientific \&Iind. Rese. 63, 55-364.

14. Noroozi B, Arami M., and Bahrami S.H. 2004. Investigation on the capability of silk worm pupa as a Natural Adsorbent for Removal of Dyes from Textile effluent. Iranian J. Chem. Engg. $1(2), 44-47$.

15. Shrihari S., and Raghavendra Kiran 2003. Adsorption of dissolved iron on laterite, Poll. Res. 22(4), 507-510.

16. Katyal S.K., and Daga K. 2003. Removal of dyes by an Adsorbent derived from Tecomella undulate in western Rajasthan, Indian J. Environ. Protection, 23(1), 37-40.

17. Malik P.K. 2003. Saw Dust and Rice-Husk for adsorption of acid dyes: a case Study of Acid Dyes, Sci. dire, Dyes and pigments, 56, 239-249.

18. Sheng H. Lin 1993. Adsorption of disperse dye by powdered activated carbon, J. Chem. Tech. Biotechnol. 53, 387 - 391.

19. Geetha K.S. and Belagali S.L. 2011. Application of natural adsorbents for dyes and industrial effluents, The Ecoscan, 5(land 2), 89-93.

20. Adamson A. W. 1960. Physical chemistry of surfaces. Interscience publ. Inc., New York.

21. Kannan N. and Vanamudi A. 1991. A study on the removal of chromium (VI) by adsorption on lignite coal. Indian J. Env. Prot.11(4): 241-245.

22. Weber T.W. and Chakravorti 1974. Pore and solid diffusion models for fixed bed adsorber . J. Am. Inst. Chem. Eng. 2: 228-238.

23. C.R.Ramakrishnaiah and D. N. Arpitha, 2014. Removal of Colour from Textile Effluent by Adsorption Using Low Cost Adsorbents,International Research Journal of Pure \& Applied Chemistry, 4(5):568-577. 